\title{
FORMAÇÃO DOCENTE PARA O TRABALHO EM SAÚDE: O "Notório Saber" e Outras Propostas de Precarizaçâo e Flexibilização
}

\author{
Maria Inês Bomfim ${ }^{1}$ \\ Valeria Morgana Goulart ${ }^{2}$
}

\begin{abstract}
RESUMO
$\mathrm{Na}$ atual conjuntura política brasileira, caracterizada por forte ajuste fiscal, os cortes orçamentários, a reforma trabalhista e os processos restritivos à manutenção plena de direitos conquistados tardiamente pela sociedade, vinculam-se à redução da participação do Estado na área social e à precarização de políticas para áreas prioritárias, como a formação de trabalhadores e de seus professores. Neste estudo, problematizamos, em especial, as tentativas de flexibilização dos requisitos ao trabalho docente, bem como o esvaziamento das políticas de formação de professores que, enaltecendo o saber profissional construído na prática, secundarizam aspectos da formação que não estão presentes na vida cotidiana dos profissionais da área de saúde. Defendemos que a vida cotidiana, embora importante, não é a única esfera da vida social. Concluímos que as esferas não cotidianas mais complexas, tais como as ciências, a filosofia e a política, por exemplo, resultado da experiência acumulada pela humanidade, podem ser decisivas no processo formativo de professores por produzir o questionamento sobre o pensar, o sentir e o agir no âmbito da saúde, evitando que a vida cotidiana se hipertrofie em relação às outras esferas e que se perca o poder da reflexão e da crítica sobre a realidade em que esses professores atuam.
\end{abstract}

Palavras-chave: Trabalho docente. Formação docente em saúde. Notório saber.

TEACHER EDUCATION FOR HEALTH PROFESSIONALS:

'RECOGNIZED ERUDITION’ AND OTHER JOB INSTABILITY AND FLEXIBILITY PROPOSALS

\begin{abstract}
In the current Brazilian political environment of strong fiscal adjustment, budget cuts, labor reforms, and restrictions to recently earned rights are linked to a decline in government social spending and the collapse of policies for priority areas such as the training of workers and their teachers. In this study, we analyzed the attempts to relax teaching requirements and the emptying out of teacher education policies, which prioritize practical professional knowledge and neglect aspects of training that are not present in the daily routine of health care professionals. We argue that everyday life, while important, is not the sole sphere of social life. We conclude that the more complex non-everyday spheres such as the sciences, philosophy, and politics, which are the result of accumulated human experience, can be crucial in the teaching process to foster questioning about thinking, feeling, and acting in health settings, preventing everyday life from taking precedence over the other spheres and that teachers lose the power to reflect and critique on the reality where they work.
\end{abstract}

Keywords: Teaching. Teacher education in health sciences. Recognized erudition.

RECEBIDO EM: 28/11/2018

ACEITO EM: 28/1/2019

\footnotetext{
${ }^{1}$ Mestre e doutora em Educação. Professora associada da Faculdade de Educação da Universidade Federal Fluminense (UFF), Niterói - RJ Brasil.mariaines.uff@gmail.com.

${ }^{2}$ Enfermeira e especialista em Gestão e Economia em Saúde. Tecnologista em Saúde da Vice-Presidência de Ensino, Informação e Comunicação da Fundação Oswaldo Cruz (Fiocruz). Rio de Janeiro-Brasil. valeria.morgana@fiotec.fiocruz.br.
} 
O tema deste estudo é a formação de professores voltada ao preparo dos trabaIhadores de nível médio da área da saúde pública na atualidade brasileira. ${ }^{3}$ Nosso objetivo é oferecer subsídios ao debate acerca das políticas recentes de flexibilização dos requisitos ao trabalho docente e dos processos de formação de professores, traduzidos, entre outras possibilidades, na contratação de profissionais sem formação pedagógica específica, isto é, os detentores do chamado "notório saber" na área. Tal proposta, já assegurada na Lei de Diretrizes e Bases da Educação Nacional, no caso da educação profissional, incluindo a área da saúde, enaltece um saber profissional construído na prática, secundarizando aspectos da formação para a docência que não estão presentes na vida cotidiana dos profissionais da área da saúde.

A formação docente, como prática social que é, insere-se em contexto de intensas mudanças para os trabalhadores em todo o mundo. Articulada, como as demais práticas sociais na crise socioeconômica, teórica e ético-política da sociedade (FRIGOTTO, 2001), a formação exige que a situemos na cena política atual, caracterizada por forte ajuste fiscal e cortes orçamentários, bem como por processos restritivos à manutenção plena de direitos sociais conquistados tardiamente pela sociedade brasileira.

Qualquer realização da experiência humana, inclusive o trabalho docente, contém, em si mesma, além de uma dimensão subjetiva, isto é, a forma como sentimos e apreendemos a realidade, uma dimensão objetiva, ou seja, as circunstâncias concretas em que vivemos, que condicionam nossas formas de sentir. As duas dimensões - objetiva e subjetiva - são indissociáveis. As condições de vida e de trabalho dos professores, de modo geral, degradaram-se muito nos últimos anos, embora esse processo não seja linear, atingindo todos os professores de todos os níveis, modalidades e redes da mesma forma, posto que as situações são bastante diversas e as perdas desiguais. De toda maneira, a situação majoritária no ensino brasileiro é a de remuneração insuficiente, condições de trabalho inadequadas e desprestígio do trabalho docente.

O trabalho em saúde é complexo, como sabemos. As tecnologias utilizadas e os diferentes espaços em que é realizado ajudam a compreender as razões dessa complexidade. Sua natureza é interdisciplinar; demanda esforço de confluência dos vários saberes de uma equipe multiprofissional. Apesar disso, a racionalização das práticas de saúde tem se caracterizado pela decomposição dos atos e intervenções realizados por vários trabalhadores diferentes, resultando em um conjunto fragmentado de atos individuais, com base em mecanismos instituídos de dominação de relações assimétricas de poder entre as várias corporações profissionais, ocultando a imprescindível colaboração que deve existir entre os trabalhadores para que o cuidado aconteça. Cuidar tem especificidades ausentes na produção de objetos pelo fato de certas características da produção de mercadorias, tal como a flexibilização e a precarização das relações de trabalho, estarem sendo incorporadas também ao trabalho que não é material (BOMFIM, 2007), como o do professor e o do profissional da área da saúde.

${ }^{3}$ Estudo realizado no âmbito das atividades do Grupo de Pesquisa Formação e Trabalho Docente em Educação Profissional da Universidade Federal Fluminense - UFF -, em parceria com a Fundação Oswaldo Cruz - Fiocruz. 
Nessa perspectiva, há desafios em relação à formação de professores de forma geral, e na área de saúde em particular. Analisando as condições de exercício profissional dos docentes em todas as áreas, Barreto e Leher (2003) identificaram, desde o início dos anos 2000, uma conexão direta entre precarização, flexibilidade e mercado, podendo-se apreender que trabalhadores "flexibilizados", sem direitos trabalhistas, reduziriam o chamado "custo Brasil". Flexível, vale lembrar, é o que se pode dobrar, curvar e que é elástico, condição considerada necessária aos novos tempos competitivos que as ideologias da globalização e do neoliberalismo defendem.

A esse respeito, Shiroma e Lima Filho (2011) relatam que os professores reportam-se à precariedade das condições contratuais, inclusive nas redes públicas, predominando os contratos temporários, sem garantias sociais. Trata-se de atividade marcada pela incerteza, mas também pela flexibilidade de horários, o que favorece a constituição da docência como um "bico", despotencializando o trabalho coletivo na escola e dificultando a construção da profissionalidade docente.

Neste estudo, partimos de um exame crítico da realidade da formação docente, em especial na área da educação profissional em saúde, reconhecendo que a insuficiência de análises comprometidas com a raiz dos problemas sociais, incluindo a formação de professores, está relacionada também à explicitação mais nítida, nas últimas décadas, de um pensamento teórico, que tem como fortes inspirações o abandono de uma postulação considerada essencial neste trabalho: a de que o destino é sempre humano e que, por isso mesmo, nunca estará esgotado (KONDER, 1992).

Buscamos situar, de forma breve, a especificidade da formação docente no campo da saúde pública e problematizamos a flexibilização das atuais exigências para a docência, mediante a contratação de profissionais com "notório saber" para a educação profissional. Defendendo a necessidade da formação docente sólida para todos os que se ocupam do trabalho de ensinar, na qual o conhecimento e a teoria não sejam secundarizados em nome da prática, indicamos que as esferas não cotidianas mais complexas, tais como as ciências, a filosofia, a política, por exemplo, resultado da experiência acumulada pela humanidade, podem ser decisivas no processo formativo para produzir 0 questionamento sobre o pensar, o sentir e o agir em saúde, em uma perspectiva crítica (BOMFIM, 2007; BOMFIM, GOULART; RUMMERT, 2017).

Nas considerações finais reafirmamos a necessidade de formação socialmente referenciada para a docência em saúde, mostramos o risco de enfraquecimento do trabalhador docente da área, asseguramos que é imprescindível a ampliação de uma hierarquia entre os professores, em razão da formação diferenciada, com valorização igualmente distinta e a provável extinção progressiva dos cursos de Licenciatura em âmbito superior da área da saúde.

\section{FORMAÇÃO DOCENTE EM SAÚDE: Especificidades do Caso Brasileiro}

$\mathrm{Na}$ atualidade brasileira a formação docente ainda é alvo de forte disputa de sentidos depois de um período curto de conquistas parciais, decorrentes da luta dos professores em torno de políticas de formação inicial e continuada. Particularmente a partir dos anos 2000, com maior ou menor intensidade, observamos, como Dambiski (2006), três eixos articulados a uma tendência de esvaziamento nas políticas para o setor: "o 
empobrecimento da noção de conhecimento, a excessiva valorização da epistemologia da prática e o enaltecimento das competências na formação (...) dos docentes, em particular" (p. 1).

Diante dos desafios da realidade do país e das próprias finalidades da educação definidas na atual legislação, frequentemente ignoradas, causa perplexidade a forma pela qual são flexibilizados os requisitos à docência. Recentemente, em estudo detalhado sobre avanços e recuos na formação docente depois da promulgação da Constituição de 1988, Freitas (2018) assinala que "há uma lógica perversa que parte do princípio de que há muita teoria e pouca prática nos cursos de formação e, portanto, há que ser aumentado o tempo das práticas (...)" (p. 517).

Modelos de qualificação, paradigmas de formação não são construções assépticas como se sabe, tampouco ações desvinculadas da realidade social em que se vive, uma vez que as necessidades de formação se originam nas mudanças ocorridas no mundo do trabalho e nas relações sociais, cenário, portanto, a ser considerado quando se procura refletir por que se faz e como se faz a formação dos trabalhadores da saúde. "A neutralidade da educação, de que resulta ser ela entendida como um quefazer puro, a serviço da formação de um tipo ideal de ser humano, desencarnado do real (...) é uma das conotações fundamentais da visão ingênua de educação" (FREIRE, 1983, p. 32). Pelo contrário, defendemos que a prática pedagógica do docente, em virtude dos saberes que divulga e produz, e que não são neutros, traz, em si, possibilidades de mediar interesses dos alunos e dos usuários que têm direito à saúde.

Cabe, neste momento, explicitar melhor o que entendemos por trabalho docente: uma ação intencional especializada que necessita de planejamento e de execução direcionada para determinados fins. Do professor, explica Gasparin (2005), é exigida uma atitude diante do conhecimento, uma maneira de preparar o que será estudado, posto que não se trabalham conteúdos por si mesmos: “a apropriação (tornar próprio) dos conhecimentos ocorre no intuito de equacionar e/ou resolver, ainda que teoricamente, as questões sociais que desafiam o professor, os alunos e a sociedade" (GASPARIN, 2005, p. 53). Não é, portanto, qualquer conteúdo que assegura a formação, mas, sim, aquele conhecimento que se mostra adequado para construir uma nova disposição mental e uma resposta apropriada aos problemas sociais (GASPARIN, 2005).

Quando tratamos da formação de docentes na área da saúde, há particularidades adicionais que somente podem ser compreendidas com base em um breve recuo aos anos 70, quando a péssima situação de saúde no Brasil, sob uma ditadura civil-militar comprometida com os grupos econômicos dominantes, foi decisiva na mobilização para a estruturação do chamado Movimento Sanitário, integrado por organizações populares, estudantis e sindicais, professores, sanitaristas e parlamentares.

$\mathrm{Na}$ Constituição de 1988, a saúde aparece, pela primeira vez, como direito de todos e dever do Estado, sendo a criação de um Sistema Único de Saúde (SUS) fundamental à concretização desse direito, mediante políticas sociais e econômicas que visem à redução do risco de doença e de outros agravos e ao acesso universal igualitário às ações e aos serviços para sua promoção, proteção e recuperação. Estados e municípios se comprometeram com a formulação, a promoção e a gestão da educação na saúde, de forma cooperada ou direta, incluindo ações para mudança nas Graduações das pro- 
fissões da saúde e na formação de trabalhadores em nível médio, de acordo com as diretrizes do SUS. A União, por seu turno, assumiu o compromisso de promover e pactuar políticas de educação permanente em saúde, apoiando técnica e financeiramente Estados e municípios no seu desenvolvimento.

No caso da educação profissional no âmbito do SUS, Ramos (2010) identifica que, a partir da I Conferência Nacional de Recursos Humanos, realizada em 1986, configurou-se a indicação da necessidade de uma articulação mais estreita entre os serviços e as instituições formadoras, de modo que o setor saúde pudesse orientar os conteúdos curriculares da formação do trabalhador do Sistema, historicamente distantes das necessidades sociais em saúde.

Nos últimos 30 anos a questão da formação das equipes do setor tornou-se preocupação crescente, em especial em razão do grande contingente de trabalhadores com precária ou nenhuma qualificação (LIMA; MATTA, 2008). Se, no entanto, a qualificação dos trabalhadores do SUS é necessidade reconhecida, a formação docente dos profissionais da área da saúde que atuam como professores na educação profissional nem sempre o foi de maneira consensual.

Poucas áreas da saúde têm os chamados cursos de Licenciatura em Nível Superior. É o caso da Enfermagem e da Psicologia, por exemplo. Pela legislação atual, cabe ao Ministério da Saúde a qualificação da força de trabalho do SUS. Desde a criação do Sistema, porém, as iniciativas têm sido descontinuadas e fragmentadas, em que pesem as lutas dos profissionais da área pelo acesso à formação docente. Além disso, a informalidade frequente do trabalho docente em Educação Profissional na área da saúde, para o qual geralmente não há concurso e plano de carreira, faz da docência na área uma atividade temporária e adicional ao trabalho do profissional de saúde, "afastando-o das discussões mais substantivas e políticas, que, por sua vez, se ressentem da sua participação efetiva, dificultada inclusive pelos múltiplos vínculos" (TORREZ, 2014, p. 141). ${ }^{4}$

O levantamento feito por Torrez (2014) indica que o número de cursos de Licenciatura na área de Enfermagem vem sendo radicalmente reduzido, assim como as políticas públicas de formação de trabalhadores em nível médio. Além disso, a autora sublinha que a historicidade dos processos de formação docente em educação profissional está intrinsecamente ligada às iníquas condições que vêm degradando e desvalorizando a educação, a saúde e nelas a profissão docente. A má qualidade da formação, das condições de trabalho e, em decorrência, da qualidade da educação e da saúde prestadas principalmente pelo setor público, "pela natureza de classe do Estado, ressente-se da falta de investimentos, continuidade e permanente atualização e avaliação no processo de sua realização, pactuados com os sujeitos envolvidos" (TORREZ, 2014, p. 259).

No final do ano de 2016, já no governo do presidente Michel Temer (2016-2018), ocorreu uma dura derrota para a saúde e a educação em virtude da aprovação, pelo Congresso Nacional do Brasil, da Emenda Constitucional no 95, que limitará por 20 anos os gastos públicos, com a finalidade de assegurar o equilíbrio nas contas públicas. O que

\footnotetext{
${ }^{4}$ Nossas recentes pesquisas já apresentam, em virtude da redução de postos de trabalho na área de Enfermagem, a contração de professores sem experiência em qualquer tipo de serviço de saúde, o que amplia o problema. 
era deficiente, portanto, será mantido por um período considerável de estagnação. A partir de 2018, os gastos federais somente poderão aumentar de acordo com a inflação acumulada, conforme o Índice Nacional de Preços ao Consumidor Amplo (IPCA).

A deterioração dos serviços já é visível. O que não era suficiente mostra-se pior. A formação docente para a área de educação profissional, por sua vez, política que nunca chegou a ocupar a merecida centralidade no âmbito do próprio SUS, tende a ser, nos próximos anos, responsabilidade individual dos próprios trabalhadores ou, simplesmente, uma exigência flexibilizada nas redes públicas e privadas de ensino.

\section{O “NOTÓRIO SABER" E OS LIMITES DA ATUAÇÃO DE PROFESSORES SEM FORMAÇÃO PARA A DOCÊNCIA}

As restrições orçamentárias, resultantes da redução das atividades do Estado na área social, concretizaram-se por um conjunto de reformas propostas com um mesmo objetivo, isto é, a redução dos gastos públicos: a da previdência social, que não teve força política suficiente para prosseguir no governo Temer, a trabalhista (2017), que alterou de modo significativo as relações de trabalho, e a reforma do nível médio de ensino (2017), da qual a educação profissional, em todas as áreas, é uma das modalidades.

No bojo da reforma do Ensino Médio brasileiro, a regulamentação da flexibilização do exercício do trabalho docente em educação profissional e, em consequência, do esvaziamento dos processos formativos específicos, chamou a atenção. Criou-se, paradoxalmente, uma regulamentação que preserva os cursos de Licenciatura em nível superior como exigência e, ao mesmo tempo, abriu-se a possibilidade de contratação de professores detentores de um "notório saber", no caso da área de educação profissional. ${ }^{5}$

O profissional "notório saber" já estava previsto na legislação brasileira no que diz respeito à docência no Ensino Superior. $O$ artigo 66 da atual Lei de Diretrizes e Bases da Educação Nacional (Lei no 9394/96) indica que a preparação para o exercício do magistério superior far-se-á em nível de Pós-Graduação, prioritariamente em programas de Mestrado e Doutorado. O "notório saber", reconhecido por universidades com curso de Doutorado em área afim, poderá suprir a exigência de título acadêmico. Nota-se, assim, que ser professor no Ensino Superior, com "notório saber" reconhecido, é uma possibilidade excepcional. A introdução dessa condição na educação profissional de nível médio, porém, tem outras feições e critérios não muito claros.

A reformulação feita, em 2017, consta do artigo 61 da Lei de Diretrizes e Bases. A Lei passou a considerar adicionalmente como profissionais da educação aqueles com "notório saber" reconhecido pelos respectivos sistemas de ensino para ministrar conteúdos de áreas afins a sua formação ou experiência profissional, atestados por titulação específica ou prática de ensino em unidades educacionais da rede pública ou privada ou das corporações privadas em que tenham atuado. Tais critérios, indicados de forma ampla, são suficientes para que qualquer pessoa, desde que já tenha ensinado

5 Inicialmente, a intenção era flexibilizar as exigências também no Ensino Médio não profissional, o que não ocorreu, em virtude de forte reação no campo da educação. 
mesmo sem formação, possa pleitear reconhecimento para desempenhar a atividade docente na educação profissional, o que acontece no meio empresarial com uma certa frequência em várias áreas, como as ligadas à Engenharia, Hotelaria, Turismo, Informática, etc.

No mesmo artigo 61, o parágrafo único indica, ainda, que a formação dos profissionais da educação, de modo a atender às especificidades do exercício de suas atividades, bem como aos objetivos das diferentes etapas e modalidades da educação básica (incluindo a profissional), terá como fundamentos: I - a presença de sólida formação básica, que propicie o conhecimento dos fundamentos científicos e sociais de suas competências de trabalho; II - a associação entre teorias e práticas, mediante estágios supervisionados e capacitação em serviço; III - o aproveitamento da formação e experiências anteriores, em instituições de ensino e em outras atividades. Como compreender tal paradoxo no texto legal, uma vez que o próprio artigo admite como docentes aqueles que não têm preparo específico? Como a expressão das disputas sobre o sentido e significado da formação docente?

Shiroma, Campos e Garcia (2005) observa que intenções políticas podem conter ambiguidades, contradições e omissões que fornecem oportunidades particulares para serem debatidas no processo de sua efetivação. "Partindo do suposto da política como processo, uma contribuição interessante para a análise (...) parece decorrer da exploração das contradições internas às formulações, posto que os textos evidenciam vozes discordantes, em disputa" (p. 5).

A redução das exigências de formação docente em nível superior para os professores de educação profissional, porém, está autorizada. Do ponto de vista da legislação federal, trata-se de um retrocesso, visto que, em 2015, de acordo com as Diretrizes Curriculares Nacionais estabelecidas pela Resolução no 2/2015, do Conselho Nacional de Educação (BRASIL, 2015, p. 8-12), , que não chegaram nem mesmo a ser absorvidas inteiramente pelos sistemas estaduais de educação e pelas instituições formadoras, as exigências formativas para o ensino profissional, incluindo a área da saúde, foram sensivelmente ampliadas, depois de anos de intenso debate.

Na referida Resolução (2015) compreende-se a docência como ação educativa e como processo pedagógico intencional e metódico, envolvendo conhecimentos específicos, interdisciplinares e pedagógicos, conceitos, princípios e objetivos da formação, que se desenvolvem na construção e apropriação dos valores éticos, linguísticos, estéticos e políticos do conhecimento, inerentes à sólida formação científica e cultural do ensinar/aprender, à socialização e construção de conhecimentos e sua inovação, em diálogo constante entre diferentes visões de mundo.

\footnotetext{
${ }^{6}$ As Diretrizes Curriculares Nacionais para a Formação Inicial e Continuada em Nível Superior de Profissionais do Magistério para a Educação Básica aplicam-se à formação de professores para o exercício da docência na Educação Infantil, no Ensino Fundamental, no Ensino Médio e nas respectivas modalidades de educação (Educação de Jovens e Adultos, Educação Especial, Educação Profissional e Tecnológica, Educação do Campo, Educação Escolar Indígena, Educação a Distância e Educação Escolar Quilombola), nas diferentes áreas do conhecimento e com integração entre elas, podendo abranger um campo específico e/ou interdisciplinar.
} 
A ênfase naquele momento (2015) era na formação docente para a ação pedagógica, que não dissocia teoria e prática em busca de uma efetiva práxis, aqui entendida como a ação que, para se aprofundar de maneira mais consequente, precisa da reflexão, do autoquestionamento, da teoria; é a teoria que remete à ação, que enfrenta o desafio de verificar seus acertos e desacertos, cotejando-os com a prática (KONDER, 1992). "A teoria é um momento necessário da práxis e essa necessidade não é um luxo: é uma característica que distingue a práxis das atividades meramente repetitivas, cegas, mecânicas, abstratas" (KONDER, 1992, p. 115).

Essa compreensão é inteiramente diversa do pragmatismo que norteia a atual flexibilização das condições de exercício docente e da aceitação do "notório saber" como professor, expressão da lógica empresarial que prescinde da formação, via contratação de "instrutores", de profissionais voltados para a prática, a um custo mais baixo. Um trabalhador de ensino precarizado, sem direitos sociais, provavelmente, uma vez que não estaria submetido à carreira docente e, devido à falta de preparo, incapaz de responder à complexidade exigida à formação para o cuidado humano em saúde.

Assim, os valores e princípios do Movimento Sanitário e as reflexões próprias do significado social do trabalho em saúde, provavelmente estarão em risco. A atual perspectiva supõe uma "aceitação do mercado como instrumento regulador da sociabilidade, em vez de afirmar a centralidade no ser humano e em suas relações com a natureza, visando atender às necessidades dos sujeitos e da sociedade" (PACHECO, 2012, p. 13).

\section{EM DEFESA DA FORMAÇÃO DOCENTE CRÍTICA E SOCIALMENTE REFERENCIADA NA ÁREA DA SAÚDE}

Flexibilizar a exigência de formação socialmente referenciada ao exercício da docência não traz contribuições ao cuidado em saúde na realidade brasileira. Pelo contrário, ao impedir o acesso ao conhecimento não cotidiano, que só o processo formativo assegura, restringe-se à leitura crítica da realidade que pode apontar novas práticas. Para tanto, a formação precisa ser capaz de formar professores, como indica Dermeval Saviani, com "uma aguda consciência da realidade em que atuam; uma adequada fundamentação teórica que lhes permita uma ação coerente; e uma satisfatória instrumentalização técnica que lhes possibilite uma ação eficaz" (SAVIANI, 2000, p. 65).

Isso requer mais do que os conhecimentos da profissão de quem ensina. Requer, como defendemos, desenvolver uma formação teórico-prática consistente para a adoção de uma ação docente crítica e emancipadora, que possibilite aos professores, de forma coletiva, escolher e desenvolver, com autonomia social e ética, formas melhores de atuação, com base nas necessidades sociais de saúde. Exige, portanto, saberes específicos de outras áreas que ajudem a enfrentar o desafio de educar outros seres humanos nessa realidade.

Compreender os limites e as possibilidades do trabalho docente exige dos professores "claridade política", diria Paulo Freire (2001, p. 46). Essa "claridade" os obrigará a ter em mente o que realmente são: professores de educação profissional na área de saúde, no Brasil do século 21, realidade marcada pela desigualdade que não se explica por si mesma, sendo resultado de um processo histórico construído por seres humanos. 
A formação docente é, assim, imprescindível, pois as esferas não cotidianas mais complexas (HELLER, 1989), tal como as ciências, a filosofia, a política, por exemplo, resultado da experiência acumulada pela humanidade, podem ser decisivas no processo formativo de professores para produzir o questionamento sobre o pensar, o sentir e o agir em saúde. Não há como abrir mão da formação para a docência, posto que a realidade em que atuamos não é aparente, nem é simples de ser conhecida em todas as suas determinações.

Na vida cotidiana, explica Agnes Heller (1989), considerando a necessidade de produção da existência, não é possível conhecer e refletir sobre o porquê de todas as coisas. Pensamento e ação visam à efetivação de forma rápida, pragmática, no menor tempo e com o menor esforço possível, tanto intelectual quanto físico, das atividades que compõem essa esfera da vida, fundamental à reprodução dos indivíduos. O pensamento cotidiano, repleto de elementos fragmentários, "orienta-se para a realização de atividades cotidianas e, nessa medida, (...) as ideias necessárias à cotidianidade jamais se elevam ao plano da teoria, do mesmo modo como a atividade humana não é práxis" (HELLER, 1989, p. 31-32). A característica dominante da vida cotidiana, sem a qual não poderíamos sobreviver, é a espontaneidade. Se, no entanto, nos satisfazemos com os saberes produzidos cotidianamente, nos distanciamos do "que Hegel chamava de 'esforço do conceito', isto é, se não reconhecermos a importância decisiva da construção rigorosa do conhecimento científico, estaremos conscientemente ou não, encalhados na superficialidade" (KONDER, 2002, p. 237-242).

Não basta, porém, compreender a realidade de forma teórica. É preciso traduzir essa compreensão em atos individuais e coletivos que, determinando uma nova maneira de pensar, de entender e julgar os fatos e as ideias, possam definir uma nova forma de agir.

Na perspectiva aqui proposta, o conhecimento na formação docente parte da prática social concreta, de uma visão confusa para o conhecimento mais profundo e substancial que, ultrapassando a aparência, permitirá ao professor ver suas conexões, relações internas, dimensões estruturais e formas de funcionamento, no sentido de aproximação da verdade, que nunca é absoluta e, portanto, sempre passível de discussão. Em outras palavras, a formação contribuirá para que os professores possam reconhecer a complexa dialética entre os constrangimentos estruturais e a ação humana transformadora nos diferentes espaços de atuação em saúde. Acentuamos, como João Luiz Gasparin, que
A prática da qual se está falando não se reduz somente ao que fazem, sentem e pensam os educandos em seu dia-a-dia. Ela é sempre, também, expressão da prá- tica social geral, da qual o grupo faz parte. Ora, isso faz compreender que, se a totalidade social é histórica e contraditória, tanto em seus componentes objetivos quanto subjetivos, o mesmo se dá com fatos, ações e situações específicas da reali- dade imediata (...) (dos futuros professores) (GASPARIN, 2005, p. 6).

Em vista da flexibilização das exigências ao exercício da docência em educação profissional na área da saúde, avaliamos que, na atual conjuntura, não é apenas a formação docente socialmente referenciada que está sendo secundarizada, mas o próprio professor. 


\section{CONSIDERAÇÕES FINAIS: \\ Subsídios ao Fortalecimento dos Processos de Formação Docente em Saúde}

Indicamos, neste trabalho, que a atual conjuntura política brasileira, caracterizada por forte ajuste fiscal, cortes orçamentários e reformas, vem gerando processos restritivos à manutenção plena de direitos conquistados tardiamente pela sociedade. Tais processos estão vinculados à redução da participação do Estado na área social e à precarização de políticas para áreas prioritárias, como a formação de trabalhadores e de seus professores.

Buscamos problematizar, em especial, as tentativas de flexibilização dos requisitos ao trabalho docente e de esvaziamento da formação de professores que, enaltecendo um saber profissional construído apenas na prática, secundarizam aspectos da formação que não estão presentes na vida cotidiana dos profissionais da área de saúde.

Em decorrência de critérios pouco demarcados na atual legislação, conclui-se que, em educação profissional, qualquer indivíduo que seja considerado apto porque já ensinou, ainda que em condições precárias, possa atuar como professor regularmente, desde que seus conhecimentos práticos sejam reconhecidos, criando-se uma espécie de atalho para a docência.

Certamente, exigências diferenciadas nas diferentes redes e instituições deverão baratear os custos da contratação dos trabalhadores docentes do setor. $O$ fato é que 0 que poderia ser considerado (a falta de formação docente) em caráter excepcional, no caso de algumas profissões, tornou-se possibilidade chancelada pelo Estado, inclusive na área da saúde. Os sistemas estaduais, responsáveis pela educação profissional de nível técnico, deverão regulamentar a questão, inclusive no que diz respeito à docência na área da saúde. Não por coincidência, a responsabilização individual dos professores pela requalificação profissional, aliada à lógica de mercado, fez com que proliferassem cursos de formação de curta duração, configurando-se uma das principais estratégias de modernização conservadora no campo da educação.

As consequências são imprevisíveis, mas pode-se indicar, por exemplo, o risco de um recuo aos padrões característicos das primeiras décadas do século passado, no Brasil, descritos pelo sociólogo brasileiro Fernando Azevedo, em 1940. Naquele momento, entre os professores, prevalecia uma forte hierarquia, originada pelas diferenças de preparação profissional, vencimentos, regalias e vantagens, e com a seguinte estratificação: a) mestre-escola ou professores primários; b) mestres e contramestres de escolas técnico-profissionais; c) professores de ensino secundário; e d) professores universitários. "A diferenciação implicava numa "distinção de classe, baseada na superioridade do ensino intelectual sobre o ensino manual" (AZEVEDO, 1940, p.192).

Neste estudo, como visto, não privilegiamos apenas a formação para o domínio dos conteúdos específicos das áreas a serem ensinados, nem exclusivamente o preparo didático para a docência. O conhecimento, historicamente ausente da formação docente, tem sido aquele que pode contribuir para superar o "como fazer" estreito, o que engloba princípios e categorias necessários à compreensão dos processos reais de trabalho em saúde, com suas múltiplas determinações. 
Defendemos que os profissionais de saúde e os professores não estão acima da sociedade, como se pairassem sobre a realidade social. As potencialidades do trabalho docente na realidade concreta em que vivemos exigem, de quem ensina, conjugar a prática pedagógica eficiente a uma ação política da mesma qualidade.

Diante disso, na nossa avaliação o conteúdo da formação docente pode ser elemento de realização do ser humano no seu ambiente social e profissional, contribuindo para melhores condições de participação nas lutas pelo direito à saúde e pelas transformações necessárias à igualdade social. Buscamos, assim, as raízes das questões a serem superadas, pois a capacidade de intervenção crítica de quem trabalha em educação e em saúde depende do grau de consciência dessa mesma realidade.

Nossos estudos indicam que retomar a centralidade da formação docente socialmente referenciada é prioridade inadiável. Com apoio em Heller (1989), ressaltamos que a vida cotidiana, embora importante, não é a única esfera da vida social. As esferas não cotidianas mais complexas podem ser decisivas para se evitar que a vida cotidiana se hipertrofie, perdendo-se o poder da reflexão e da crítica sobre a realidade em que se atua.

Nessa direção, defendemos que é preciso assegurar aos professores de educação profissional na área da saúde os requisitos necessários à compreensão ampla da realidade na qual se inscrevem as práticas pedagógicas e de saúde, condição fundamental à participação ativa no processo de ensino-aprendizagem e à atuação crítica nas lutas coletivas pela transformação dessa mesma realidade. Para isso, será preciso desvelar a causalidade dos fenômenos sociais e suas conexões internas e externas, o que somente é possível quando existe formação. Retomar, portanto, o debate sobre a formação, em nível superior, não é questão menor neste momento.

Cabe, ainda, pensar a formação docente no âmbito das contradições presentes nos espaços de formação, ressaltando as suas possibilidades concretas de mediação dos interesses da maioria da população que têm direito à saúde, exatamente porque a prática pedagógica é prática contraditória, alvo de disputa pelo saber que se divulga e da articulação deste saber com os interesses dos sujeitos que participam dos processos de educação profissional.

Nossos estudos (BOMFIM, 2007, 2010; BOMFIM; GOULART, 2017; BOMFIM; GOULART; RUMMERT, 2017) vêm reafirmando, de forma crítica, que somos todos protagonistas de uma história que se constrói todos os dias e que precisa, também nos processos formativos, resgatar o ser humano como medida de todas as coisas.

Embora o pensamento crítico brasileiro na educação, assim como na saúde, não seja único, é possível identificar, nas várias concepções, algumas premissas básicas: a de que a educação e a saúde se relacionam de forma dialética com a sociedade, isto é, são influenciadas, mas também capazes de influenciar o todo social; que, por isso mesmo, a fonte do trabalho de ensinar é, essencialmente, a sociedade em que se vive e, ainda, que o pensamento crítico não secundariza os conteúdos, nem postula qualquer forma de ensinar.

A oferta de bases para a construção de outras práticas nessa área nos parece essencial, sem desconsiderar, de um lado, que o trabalho em saúde é fortemente marcado pela divisão técnica e, de outro, que as efetivas transformações na realidade em saúde e em educação demandam transformações no modelo social. 
Sem pretender esgotar o amplo e necessário debate a ser feito no campo da formação docente em saúde, reafirmamos que o destino da sociedade brasileira não está predeterminado. Em vista disso, para agir criticamente é preciso saber para que se age, o que conservar e o que superar, deixando claro o potencial dos processos formativos.

\section{REFERÊNCIAS}

AZEVEDO, Fernando. Sociologia educacional: introdução ao estudo dos fenômenos educacionais e de suas relações com outros fenômenos sociais. São Paulo: Melhoramentos, 1940.

BARRETO, Roberto; LEHER, Raquel. Trabalho docente e reformas neoliberais. In: OLIVEIRA, Dalila Andrade (org.). Reformas educacionais na América Latina e os trabalhadores docentes. Belo Horizonte: Autêntica, 2003. BOMFIM, Maria Inês. Trabalho docente na escola pública brasileira: as finalidades humanas em risco. In: CIAVATTA, Maria; REIS, Ronaldo (org.). A pesquisa histórica em trabalho e educação. 1. ed. Brasília: Líber Livro Editora, 2010. p. 89-111.

BOMFIM, Maria Inês (coord.). Trabalho, saúde e educação. Rio de Janeiro: Fiocruz; ENSP, 2007.

BOMFIM, Maria Inês; GOULART; Valéria Morgana; RUMMERT, Sonia Maria. Educação profissional em saúde: o sentido da escola pública e democrática. Revista Cocar (on-line), v. 3, p. 322-343, 2017. Disponível em: https://paginas.uepa.br/seer/index.php/cocar/article/view/1294. Acesso em: 22 abr. 2018.

BOMFIM, Maria Inês; GOULART, Valéria Morgana. Gerencialismo e avaliação de políticas de formação docente: a força dos indicadores socialmente referenciados. Temas em Educação e Saúde, v. 13, p. 286-300, 2017. Disponível em: https://periodicos.fclar.unesp.br/tes/article/view/10677/6918. Acesso em: 22 abr. 2018.

BRASIL. Senado Federal. Lei n.9.394, de 20 de dezembro de 1996. Estabelece as diretrizes e bases da educação nacional. Diário Oficial da União, Brasília, 23 dez. 1996. Seção 1, p. 27.833.

BRASIL. Conselho Nacional de Educação. Resolução CNE/CP 2/2015. Diário Oficial da União, Brasília, 2 de julho de 2015. Seção 1, p. 8-12.

DAMBISKI, Kátia Cristina. Trabalho e formação docentes: tendências no plano das políticas e da literatura especializada. Trabalho apresentado no GT - Trabalho e Educação - 29a Reunião da Anped. Caxambu, MG, out. 2006. Disponível em: http://www.anped.org.br/sites/default/files/gt09-1759-int.pdf. Acesso em: 4 out. 2015.

FREIRE, Paulo. A importância do ato de ler em três artigos que se complementam. 5. ed. São Paulo: Cortez Editora, 1983.FREIRE, Paulo. Política e educação: ensaios. São Paulo: Cortez, 2001.

FREITAS, Helena de. 30 anos da Constituição - avanços e retrocessos na formação de professores. Revista Retratos da Escola, Brasília, v. 12, n. 24, p. 511-527, nov./dez. 2018. Disponível em: http://retratosdaescola.emnuvens.com.br/rde/article/view/912/pdf. Acesso em: 7 fev. 2019.

FRIGOTTO, Gaudêncio. A produtividade da escola improdutiva: um reexame das relações entre educação e estrutura econômico-social capitalista. São Paulo: Cortez Editora, 2001.

GASPARIN, José Luís. Uma didática para a pedagogia histórico crítica. Campinas: Autores Associados, 2005. HELLER, Agnes. O cotidiano e a história. Rio de Janeiro: Paz e Terra, 1989.

KONDER, Leandro. A questão da ideologia. São Paulo: Companhia das Letras, 2002.

KONDER, Leandro. O futuro da filosofia da práxis: o pensamento de Marx no século XXI. Rio de Janeiro: Paz e Terra, 1992.

LIMA, Julio; MATTA, Gustavo. Estado, sociedade e formação profissonal em saúde: contradições e desafios em 20 anos de SUS. Rio de Janeiro: Editora Fiocruz, 2008.

PACHECO, Eliezer (org.). Perspectivas da educação profissional técnica de nível médio. Proposta de Diretrizes Curriculares Nacionais. Brasília: Secretaria de Educação Profissional e Tecnológica, 2012.

RAMOS, Marise. Trabalho, educação e correntes pedagógicas no Brasil: um estudo a partir da formação dos trabalhadores técnicos da saúde. Rio de Janeiro: EPSJV; UFRJ, 2010.

SAVIANI, Dermeval. Educação: do senso comum à consciência filosófica. Campinas: Autores Associados, 2000. SHIROMA, Eneida Oto; LIMA FILHO, Domingos. Trabalho docente na educação profissional e tecnológica e no Proeja. Educação \& Sociedade, Campinas, v. 32, n. 116, p. 725-743, jul./set. 2011.

SHIROMA, Eneida Oto; CAMPOS, Roselane Fátima; GARCIA, Rosalba Maria Cardoso. Decifrar textos para compreender a política: subsídios teórico-metodológicos para análise de documentos. Perspectiva, Florianópolis, v. 23, n. 2, p. 427-446, jan. 2005. ISSN 2175-795X.

Disponível em: https://periodicos.ufsc.br/index.php/perspectiva/article/view/9769. Acesso em: 9 fev. 2019. TORREZ, Milta. Políticas de formação docente para a educação profissional técnica na área da saúde, na perspectiva da reforma sanitária. 2014. 307p. Tese (Doutorado) - Faculdade de Educação, Unicamp, Campinas, 2014. 